\title{
Vitrectomy and silicone oil tamponade with and without phacoemulsification in the management of rhegmatogenous retinal detachment: A comparative study
}

\begin{tabular}{|c|c|}
\hline \multicolumn{2}{|c|}{ 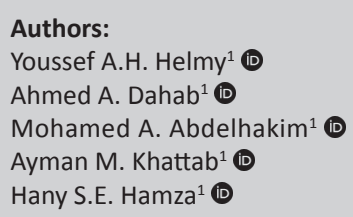 } \\
\hline \multicolumn{2}{|c|}{$\begin{array}{l}\text { Affiliations: } \\
{ }^{1} \text { Department of } \\
\text { Ophthalmology, Faculty of } \\
\text { Medicine, Cairo University, } \\
\text { Cairo, Egypt }\end{array}$} \\
\hline \multicolumn{2}{|c|}{$\begin{array}{l}\text { Corresponding author: } \\
\text { Youssef Helmy, } \\
\text { youssefhelmy@cu.edu.eg }\end{array}$} \\
\hline \multicolumn{2}{|c|}{$\begin{array}{l}\text { Dates: } \\
\text { Received: } 17 \text { Nov. } 2019 \\
\text { Accepted: } 03 \text { May } 2020 \\
\text { Published: } 06 \text { Aug. } 2020\end{array}$} \\
\hline \multicolumn{2}{|c|}{$\begin{array}{l}\text { How to cite this article: } \\
\text { Helmy YAH, Dahab AA, } \\
\text { Abdelhakim MA, Khattab AM, } \\
\text { Hamza HSE. Vitrectomy and } \\
\text { silicone oil tamponade with } \\
\text { and without } \\
\text { phacoemulsification in the } \\
\text { management of } \\
\text { rhegmatogenous retinal } \\
\text { detachment: A comparative } \\
\text { study. Afr Vision Eye Health. } \\
\text { 2020;79(1), a546. https://doi. } \\
\text { org/10.4102/aveh.v79i1.546 }\end{array}$} \\
\hline \multicolumn{2}{|c|}{$\begin{array}{l}\text { Copyright: } \\
\text { (c) 2020. The Author(s). } \\
\text { Licensee: AOSIS. This work } \\
\text { is licensed under the } \\
\text { Creative Commons } \\
\text { Attribution License. }\end{array}$} \\
\hline \multicolumn{2}{|l|}{ Read onlin } \\
\hline 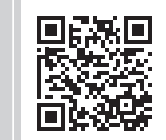 & $\begin{array}{l}\text { Scan this QR } \\
\text { code with your } \\
\text { smart phone or } \\
\text { mobile device } \\
\text { to read online. }\end{array}$ \\
\hline
\end{tabular}

Background: A cataract inevitably develops after pars plana vitrectomy (PPV) with silicone tamponade. In patients with rhegmatogenous retinal detachment (RRD) of presbyopic age and without significant cataracts, phacoemulsification can be deferred to the time of silicone removal. Alternatively, it can be performed with PPV. Sparse evidence exists to choose one option over the other; this is usually left to the surgeon's preference.

Aim: To compare PPV with silicone tamponade alone, or combined with phacoemulsification for primary RRD, in patients without significant cataracts.

Setting: This is a comparative prospective randomised interventional study that was conducted in Cairo University hospitals.

Methods: The patients were randomised to two groups, each with 20 phakic patients presenting with RRD. Patients in Group A were randomised to PPV, followed by the phacosilicone removal. Patients in Group B were randomised to phaco-vitrectomy, followed by silicone removal.

Results: No statistically significant difference existed between the groups regarding the rate of intraoperative complications. Group B patients had a higher rate of early postoperative complications (intraocular pressure [IOP], corneal oedema and anterior chamber reaction). At final follow-up there was no statistically significant difference between the groups regarding the rate of retinal attachment or the best corrected visual acuity. Calculation of lens power was significantly more accurate in Group A, as evidenced by the difference in the mean spherical equivalent (Group A: -0.75 dioptre [D] vs Group B: $-2.5 \mathrm{D}, p=0.031$ ).

Conclusion: This study suggests that no difference exists between the surgical options regarding anatomical success and intraoperative complications. Deferring phacoemulsification until the time of silicone oil removal offers an option with fewer early postoperative complications and more accurate lens power calculation.

Keywords: Rhegmatogenous retinal detachment; pars plana vitrectomy; silicone oil tamponade; phaco-vitrectomy; phaco-silicone removal.

\section{Introduction}

Following pars plana vitrectomy (PPV) with silicone oil tamponade, a cataract inevitably develops. ${ }^{1}$ This is related to the accelerated oxidative damage that the lens undergoes in the absence of the vitreous body, ${ }^{2}$ in addition to the effect that silicone oil has on the development of a cataract. ${ }^{1,3}$ Accordingly, there are two surgical possibilities: either performing a lens-sparing vitrectomy and postponing phacoemulsification with silicone removal, or performing a combined phacoemulsification and PPV, followed by silicone oil removal (SOR). ${ }^{4}$

Performing a staged procedure is advocated to overcome some of the intraoperative difficulties and postoperative complications that may occur with a combined procedure. These complications would not normally occur with vitrectomy alone, including corneal oedema, narrow pupil intraoperatively, and anterior chamber reaction with fibrinous exudate formation and posterior capsular opacification postoperatively. ${ }^{5}$ 
The concept of combining phacoemulsification with PPV emerged to overcome some of the intraoperative difficulties of PPV alone. This was especially so after facilitating the ease of removing the vitreous base without the added risk of touching the crystalline lens and ensuring the identification of peripheral retinal breaks. It also addressed the difficulties of performing a later cataract extraction on a vitrectomised eye, with the risk of capsular tears. ${ }^{6}$

The aim of this study was to compare performing PPV alone or combined with phacoemulsification and intraocular lens implantation for primary rhegmatogenous retinal detachment (RRD) in patients without significant cataracts, specifically the ease, success rate and safety with less documented intraoperative difficulties and postoperative complications.

\section{Subjects and methods}

This was a comparative prospective randomised interventional study applied on two comparative groups: Group A and Group B. Each group had 20 patients who had a total of 20 phakic eyes and were presenting with RRD. Pars plana vitrectomy with silicone oil tamponade was done as the primary procedure in Group A, which was followed three months later by a combined phacoemulsification and SOR. The primary procedure for Group B was a combined phacovitrectomy and this was followed 3 months later by SOR. There was a follow-up period of 1 month postoperatively after the second procedure in both groups. All procedures were performed by two senior consultant vitreoretinal surgeons (one in each group), with a vitreoretinal fellow at trainee level who worked with both surgeons and under their supervision. The study was conducted after approval from the Ethics Committee at Cairo University, and all patients gave informed consent. The study was conducted in accordance with the tenets of the Declaration of Helsinki.

\section{Patient selection}

Patients included had RRD and phakic eyes with a clear lens or any lenticular opacity not precluding fundus examination, and were 40 years or older at presentation. Patients were excluded if they had a recurrent or tractional retinal detachment (RD), proliferative vitreoretinopathy (PVR) grade $\mathrm{C}$ in 2 clock hours or worse, if their intraocular pressure (IOP) was higher than $21 \mathrm{mmHg}$ at initial examination or if they had a cataract that precluded fundus examination.

Patients were recruited from two specialised retina clinics in Cairo University hospitals on two separate days. Quasi randomisation was achieved by sequentially assigning patients attending the first clinic to Group A and patients attending the second clinic to Group B.

\section{Preoperative assessment}

All patients had a complete ophthalmological examination before surgery including autorefraction and best corrected visual acuity (BCVA), a slit-lamp examination of the anterior segment, an assessment of IOP, and a dilated fundus examination by binocular slit-lamp biomicroscopy and by indirect ophthalmoscopy (with the aid of scleral indentation).

Group B patients had optical biometry performed using the Haag-Streit ${ }^{\circledR}$ optical biometry machine. An intraocular lens (IOL) was selected to achieve around -0.50 dioptre (D) postoperative refraction.

\section{Group A: Pars plana vitrectomy followed by phaco-silicone removal}

A 23-gauge, three-port PPV was performed, starting with a core vitrectomy and detachment of the posterior hyaloid. Perfluorocarbon liquid was used to flatten the mobilised retina, followed by shaving of the vitreous base. Endolaser photocoagulation was applied to all of the retinal breaks. Fluid-air exchange was performed followed by a silicone oil 1000 Centistokes injection. Sclerotomy sites were meticulously examined for any leaks and sutured if their self-sealing ability was in doubt, using $7 / 0$ vicryl sutures. Patients were seen on the first day of the first week and then every month for three months. Additional visits could be scheduled to follow up on any issues.

All patients were scheduled for silicone removal, to begin after the third month visit. During each visit, an examination similar to the preoperative assessment was performed. At the final postoperative visit, optical biometry was performed using the Haag-Streit ${ }^{\circledR}$ optical biometry machine. An IOL was selected to achieve around $-0.50 \mathrm{D}$ postoperative refraction. Silicone oil removal was also performed through a 23-gauge, three-port system. After fashioning the three sclerotomies and keeping the cannulae closed with plugs, any emulsified oil in the anterior chamber was expressed by injecting viscoelastic. Phacoemulsification was then performed through a $2.8 \mathrm{~mm}$ clear corneal incision, followed by irrigation or aspiration of the cortex and then IOL implantation. The clear corneal incision was then sutured with a single 10-0 nylon suture. Silicone was removed using a viscous fluid extraction syringe attached to the vitrectomy machine and utilising active suction. Emulsified oil was removed through repeated fluid-air exchange. The retina was then examined. Sclerotomy sites were meticulously examined for any leaks and sutured if their self-sealing ability was in doubt by $7 / 0$ vicryl sutures.

\section{Group B: Combined phacovitrectomy followed by silicone oil removal}

After fashioning the three sclerotomies and keeping the cannulae closed with plugs, phacoemulsification was performed. This was followed by IOL implantation, and then by PPV as previously outlined. Patients in this group had the same postoperative schedule and at three months were scheduled for SOR. The anterior chamber was not accessed unless emulsified oil prevented visualisation. At the end of every procedure, the surgeon was asked to fill 
out a questionnaire to define any intraoperative difficulties and to confirm the execution of the surgical steps.

\section{Postoperative assessment}

At the final follow-up, at one month after the second procedure, all patients had a complete ophthalmological examination including autorefraction and BCVA, a slit-lamp examination of the anterior segment, an assessment of IOP, and a dilated fundus examination by binocular slit-lamp biomicroscopy and by indirect ophthalmoscopy.

\section{Primary outcomes}

The primary outcome of this study was to compare the two groups in terms of anatomical success (defined as the reattachment of the retina, until the end of the follow-up period, including follow-up after the removal of the silicone oil), and to compare the rate of intraoperative and postoperative complications according to the questionnaire answers given by the surgeons.

\section{Secondary outcomes}

The secondary outcome of this study was to compare the functional success of both groups (defined by BCVA at the final conclusion visit after SOR) and the difference between the two groups in terms of the accuracy of preoperative biometry, as evidenced by the difference in manifest refraction at the final conclusion visit.

\section{Statistical methods}

Data were initially processed using Excel (Microsoft Office 2016) and then transferred for further analysis using the Statistical Package for Social Sciences (International Business Machines Corporation [IBM] 2009). Non-parametric variables (age, IOP, BCVA, etc.) were expressed as mean and range. For intraoperative and postoperative complications (parametric variables), the rate of a complication was calculated by dividing the number of occurrences by the total number of patients in the group (20). They were expressed both as a percentage and as an absolute number. The difference between parametric variables with two possible outcomes was compared for statistical significance using the Pearson's chi-square test. Parametric variables with three or more possible outcomes were compared using the Fisher's exact test. Non-parametric variables were compared using the Mann-Whitney test or the one-paired T-test. Correlations were calculated using Pearson's correlation coefficient. Statistical significance was considered when the $p$-value was found to be less than 0.05 .

\section{Results}

Males comprised $60 \%$ of patients in Group A $(n=12)$ and $70 \%$ of patients in Group B $(n=14)$. The mean age of patients in Group A was 57.55 years (45-70) and in Group B, 56.75 years (42-72). There was no statistically significant difference in the sex $(p=0.507)$ or mean age $(p=0.674)$ between the patients in both groups. A summary of preoperative data for both groups is shown in Table 1. There was no statistical difference in mean preoperative BCVA, lens status, pattern of RD, macular status or PVR. Mean preoperative IOP was higher in Group B (12.95 [10 $\mathrm{mmHg}-16 \mathrm{mmHg}])$ than in Group A (11.06 [8 mmHg - $20 \mathrm{mmHg}])$ and the difference was statistically significant $(p=0.041)$. However, IOP in both groups was within normal limits and the difference was not clinically significant.

\section{First procedure operative data: Pars plana vitrectomy Group A versus pars plana vitrectomy Group B}

The questions which yielded answers that displayed complications or answers that showed differences between the groups were those concerning the development of corneal oedema during PPV, the number of breaks seen intraoperatively as compared to preoperatively, the detachment of the posterior hyaloid, shaving of the vitreous base, posterior capsular touch, fluid-air exchange and the digital tension at the end of the procedure. Despite the clinical difference between the two groups, there was no statistically significant difference between them. A summary of the positive findings and their comparison is shown in Table 2.

\section{First procedure postoperative data}

The main significant difference between the two groups was in the mean postoperative IOP: It was higher in

TABLE 1: Preoperative data for both groups.

\begin{tabular}{lccccccc}
\hline Preoperative findings & \multicolumn{2}{c}{ Group A } & & \multicolumn{3}{c}{ Group B } & \multirow{2}{*}{-value } \\
\cline { 2 - 3 } \cline { 6 - 7 } & $\%$ & Number & & $\%$ & Number & \\
\hline Clear lens & 45 & 9 & & 35 & 7 & 0.519 \\
Faint cataract & 55 & 11 & & 65 & 13 & \\
Total RD macula-on & 5 & 1 & & 5 & 1 & 0.337 \\
Sub-total RD macula-off & 45 & 9 & & 60 & 12 & \\
Total RD & 55 & 10 & & 35 & 7 & \\
PVR A & 45 & 9 & & 70 & 14 & 0.320 \\
PVR B & 55 & 11 & & 30 & 6 & \\
Mean LogMAR BCVA & - & - & & - & - & 0.263 \\
Mean IOP & - & - & & - & - & 0.041 \\
\hline
\end{tabular}

Mean IOP, Group A $=11.06(8 \mathrm{mmHg}-20 \mathrm{mmHg})$; Group B $=12.95(10 \mathrm{mmHg}-$ $16 \mathrm{mmHg}$ ).

Mean LogMAR BCVA, Group A = 2.305 (3-1); Group B $=2.44$ (3.0-0.3).

$R D$, retinal detachment; PVR, proliferative vitreoretinopathy; BCVA, best corrected visual acuity; IOP, intraocular pressure.

TABLE 2: First procedure intraoperative data.

\begin{tabular}{lccccccc}
\hline Intraoperative findings & \multicolumn{3}{c}{ Group A } & & \multicolumn{2}{c}{ Group B } & \multirow{2}{*}{$\boldsymbol{p}$-value } \\
\cline { 2 - 3 } \cline { 6 - 7 } & $\mathbf{\%}$ & Number & & $\%$ & Number & \\
\hline Corneal oedema & 0 & 0 & & 10 & 2 & 0.147 \\
Difficult trocar insertion & 0 & 0 & & 5 & 1 & 0.311 \\
More breaks identified & 25 & 5 & & 10 & 2 & 0.212 \\
Breaks during PVD & 10 & 2 & & 5 & 1 & 0.513 \\
Breaks during vitreous base shaving & 0 & 0 & & 5 & 1 & 0.311 \\
Post capsular touch & 5 & 1 & & 5 & 1 & 1.000 \\
Slippage during fluid-air exchange & 0 & 0 & & 15 & 3 & 0.100 \\
Soft digital tension at conclusion & 0 & 0 & & 5 & 1 & 0.311 \\
\hline
\end{tabular}

PVD, posterior vitreous detachment. 
Group B (16.6 mmHg [6 $\mathrm{mmHg}-29 \mathrm{mmHg}])$ than in Group A (12.1 mmHg [8 $\mathrm{mmHg}-16 \mathrm{mmHg}])$ on the first postoperative day. This difference was statistically significant $(p=0.002)$. Subsequently, 13 patients in Group B $(65 \%)$ needed antiglaucoma drops, beginning on the first postoperative day, whilst no patients in Group A needed antiglaucoma drops; the difference was also statistically significant $(p<0.001)$. This significant difference continued throughout the first month, with 11 patients in Group B versus four patients in Group A requiring antiglaucoma drops $(p=0.022)$

In addition, at the first week follow-up, 14 patients in Group B (70\%) showed abnormal anterior chamber (AC) contents (cells and flare) and six patients (30\%) had corneal oedema, whilst no patients in Group A showed either. The difference between the groups in both of these issues was significant ( $p=0.001$ and $p=0.008$, respectively). At the 3-month follow-up before SOR, the mean IOP in Group A was $16.35 \mathrm{mmHg}(11 \mathrm{mmHg}-30 \mathrm{mmHg})$, whilst in Group B it was $12.9 \mathrm{mmHg}(10 \mathrm{mmHg}-17 \mathrm{mmHg})$. The difference was statistically significant $(p=0.017)$. Also, 11 patients in Group B (55\%) had emulsified silicone oil in the AC, while only one patient in Group A (5\%) had emulsified oil in the AC. The difference was also statistically significant $(p=0.001)$. No patients in either group had recurrent RDs under silicone oil. A summary of the postoperative data for both groups is given in Table 3 .

\section{Second procedure operative data: Silicone oil removal Group A versus silicone oil removal Group B}

There was a difference between the groups regarding the rates of intraoperative corneal oedema, status of the pupil during SOR, additional procedures performed after silicone removal, status of the vitreous base and digital tension of the globe at the end of the procedure. Despite the clinical difference between the groups, no statistically significant difference existed between them when SOR was compared. A summary is shown in Table 4.

\section{Phaco Group A versus phaco Group B}

There was a difference between the groups in the status of the pupil during phacoemulsification, complications during capsulorhexis, difficulties related to irrigation or aspiration of the cortex and IOL implantation. Despite the clinical difference between the two groups, there was no statistically significant difference between them. A summary is shown in Table 5.

TABLE 3: First procedure postoperative data.

\begin{tabular}{|c|c|c|c|c|c|c|}
\hline \multirow[t]{2}{*}{ Visit } & \multirow[t]{2}{*}{ Postoperative findings } & \multicolumn{2}{|c|}{ Group A } & \multicolumn{2}{|c|}{ Group B } & \multirow[t]{2}{*}{$p$} \\
\hline & & $n$ & $\%$ & $n$ & $\%$ & \\
\hline \multirow[t]{6}{*}{ Day 1} & Mean IOP & \multicolumn{2}{|c|}{$12.1(8 \mathrm{mmHg}-16 \mathrm{mmHg})$} & \multicolumn{2}{|c|}{$16.6(6 \mathrm{mmHg}-29 \mathrm{mmHg})$} & 0.002 \\
\hline & Anti-glaucoma drugs & 0 & 0 & 13 & 65 & $<0.001$ \\
\hline & Corneal oedema & 0 & 0 & 9 & 45 & 0.001 \\
\hline & Abnormal AC contents & 5 & 25 & 19 & 95 & $<0.001$ \\
\hline & Posterior synechiae & 0 & 0 & 0 & 0 & 1 \\
\hline & Attached retina & 20 & 100 & 20 & 100 & 1 \\
\hline \multirow[t]{6}{*}{ Week 1} & Mean IOP & \multicolumn{2}{|c|}{$17.65(12 \mathrm{mmHg}-30 \mathrm{mmHg})$} & \multicolumn{2}{|c|}{$17.2(10 \mathrm{mmHg}-45 \mathrm{mmHg})$} & 0.241 \\
\hline & Anti-glaucoma drugs & 2 & 10 & 13 & 65 & 0.001 \\
\hline & Corneal oedema & 0 & 0 & 6 & 30 & 0.008 \\
\hline & Abnormal AC contents & 0 & 0 & 14 & 70 & $<0.001$ \\
\hline & Posterior synechiae & 0 & 0 & 2 & 10 & 0.147 \\
\hline & Attached retina & 20 & 100 & 20 & 100 & 1 \\
\hline \multirow[t]{6}{*}{ Month 1} & Mean IOP & \multicolumn{2}{|c|}{$16.6(11 \mathrm{mmHg}-38 \mathrm{mmHg})$} & \multicolumn{2}{|c|}{$13.3(8 \mathrm{mmHg}-18 \mathrm{mmHg})$} & 0.053 \\
\hline & Anti-glaucoma drugs & 4 & 20 & 11 & 55 & 0.022 \\
\hline & Corneal oedema & 0 & 0 & 2 & 10 & 0.147 \\
\hline & Abnormal AC contents & 0 & 0 & 5 & 25 & 0.047 \\
\hline & Posterior synechiae & 0 & 0 & 2 & 10 & 0.147 \\
\hline & Attached retina & 20 & 100 & 20 & 100 & 1 \\
\hline \multirow[t]{6}{*}{ Month 2} & Mean IOP & \multicolumn{2}{|c|}{$15.55(10 \mathrm{mmHg}-20 \mathrm{mmHg})$} & \multicolumn{2}{|c|}{$14.2(7 \mathrm{mmHg}-25 \mathrm{mmHg})$} & 0.151 \\
\hline & Anti-glaucoma drugs & 3 & 15 & 5 & 25 & 0.429 \\
\hline & Corneal oedema & 0 & 0 & 1 & 5 & 0.311 \\
\hline & Abnormal AC contents & 0 & 0 & 2 & 10 & 0.106 \\
\hline & Posterior synechiae & 0 & 0 & 2 & 10 & 0.147 \\
\hline & Attached retina & 20 & 100 & 20 & 100 & 1 \\
\hline \multirow[t]{6}{*}{ Month 3} & Mean IOP & \multicolumn{2}{|c|}{$16.35(11 \mathrm{mmHg}-30 \mathrm{mmHg})$} & \multicolumn{2}{|c|}{$12.9(10 \mathrm{mmHg}-17 \mathrm{mmHg})$} & 0.017 \\
\hline & Anti-glaucoma drugs & 3 & 15 & 7 & 35 & 0.144 \\
\hline & Corneal oedema & 0 & 0 & 1 & 5 & 0.311 \\
\hline & Abnormal AC contents & 1 & 5 & 11 & 55 & $<0.001$ \\
\hline & Posterior synechiae & 0 & 0 & 3 & 15 & 1 \\
\hline & Attached retina & 20 & 100 & 20 & 100 & 1 \\
\hline
\end{tabular}

Note: The data in bold indicate statistically significant results.

$\mathrm{IOP}$, intraocular pressure; $\mathrm{AC}$, anterior chamber. 


\section{Second procedure postoperative data}

The main significant difference between the groups was the need to administer antiglaucoma drops. On the first postoperative day, seven patients in Group B needed drops versus five patients in Group A ( $p=\mathrm{G0.049)}$. Throughout the first week, all of the patients in Group A no longer required antiglaucoma drops, whereas the seven patients in Group B still needed them $(p=0.004)$. By the final follow-up, more patients in Group B were on antiglaucoma drops; however, the difference was not statistically significant. In addition, more patients in Group A had early postoperative corneal oedema (in the first week). Regarding anatomical success

TABLE 4: Second procedure operative data: Silicone oil removal Group A versus silicone oil removal Group B.

\begin{tabular}{|c|c|c|c|c|c|}
\hline \multirow[t]{2}{*}{ Intraoperative findings } & \multicolumn{2}{|c|}{ Group A } & \multicolumn{2}{|c|}{ Group B } & \multirow[t]{2}{*}{$p$-value } \\
\hline & $\%$ & Number & $\%$ & Number & \\
\hline Corneal oedema before SOR & 10 & 2 & 5 & 1 & 0.548 \\
\hline Narrow pupil before or during SOR & 15 & 3 & 15 & 3 & 1.000 \\
\hline Additional procedure after SOR & 5 & 1 & 5 & 1 & 1.000 \\
\hline No visible vitreous base remnants & 65 & 13 & 60 & 12 & 0.744 \\
\hline Vitreous base can't be examined & 35 & 7 & 40 & 8 & \\
\hline Soft tension digitally & 10 & 2 & 10 & 2 & 1.000 \\
\hline
\end{tabular}

Additional procedure after SOR: Group A = ERM peel; Group B = Post capsulotomy. SOR, silicone oil removal; ERM, epiretinal membrane.

TABLE 5: Phaco Group A versus phaco Group B.

\begin{tabular}{lcccccccc}
\hline Intraoperative findings & \multicolumn{2}{c}{ Group A } & & \multicolumn{2}{c}{ Group B } & \multirow{2}{*}{$p$-value } \\
\cline { 2 - 3 } \cline { 6 - 8 } & $\mathbf{\%}$ & Number & & $\%$ & Number & \\
\hline Narrow pupil during phaco & 5 & 1 & & 0 & 0 & 0.311 \\
Extended capsulorhexis & 5 & 1 & & 10 & 2 & 0.548 \\
Complicated I/A & 5 & 1 & & 5 & 1 & 1.000 \\
\hline
\end{tabular}

$\mathrm{I} / \mathrm{A}$, irrigation/aspiration. at the final follow-up; one patient in Group A developed a recurrent RD 1 week after SOR; however, there was no statistically significant difference between the two groups. In terms of functional success, there was no statistically significant difference between the groups in final BCVA; however, the mean spherical equivalent of the manifest refraction of patients in Group A was $-0.75 \mathrm{D}(+1.25 \mathrm{D}$ to $-3.25 \mathrm{D})$, whilst in Group B it was $-2.5 \mathrm{D}(+1.5 \mathrm{D}$ to $-6.6 \mathrm{D})$. There was a statistically significant difference in the spherical equivalent of the refraction in the groups at final follow-up $(p=0.031)$. A summary is shown in Table 6.

\section{Discussion}

This study was designed to answer a simple question: If a patient who is 40 years or older and who doesn't have a significant cataract, develops RRD, is it better to perform a lens-sparing PPV and defer the cataract extraction and IOL implantation with SOR? Or is it better to perform a combined PPV with cataract extraction and IOL implantation followed by SOR later on?

The outcomes of the study were used to define which procedure is the better option. They included the rate of attaining postoperative attachment at the final follow-up visit and the difference in intraoperative and postoperative complications between both procedures (primary outcomes). They also included the difference in final BCVA and accuracy of the IOL power calculation (secondary outcomes).

The timing of the removal of the crystalline lens did not appear to influence the rate of re-detachment in our study or

TABLE 6: Second procedure postoperative data.

\begin{tabular}{|c|c|c|c|c|c|c|}
\hline \multirow[t]{2}{*}{$\overline{\text { Visit }}$} & \multirow[t]{2}{*}{ Postoperative findings } & \multicolumn{2}{|c|}{ Group A } & \multicolumn{2}{|c|}{ Group B } & \multirow[t]{2}{*}{$p$-value } \\
\hline & & $n$ & $\%$ & $n$ & $\%$ & \\
\hline \multirow[t]{6}{*}{ Day 1} & Mean IOP & $11.55 \dagger$ & - & $9.4 \dagger$ & - & 0.073 \\
\hline & Anti-glaucoma drugs & 5 & 25 & 7 & 35 & 0.049 \\
\hline & Corneal oedema & 16 & 80 & 11 & 55 & 0.091 \\
\hline & Abnormal AC contents & 16 & 80 & 11 & 55 & 0.252 \\
\hline & Posterior synechiae & 0 & 0 & 0 & 0 & 1 \\
\hline & Attached retina & 20 & 100 & 20 & 100 & 1 \\
\hline \multirow[t]{6}{*}{ Week 1} & Mean IOP & $13.95 \S$ & - & 16.55 & - & 0.459 \\
\hline & Anti-glaucoma drugs & 0 & 0 & 7 & 35 & 0.004 \\
\hline & Corneal oedema & 9 & 45 & 2 & 10 & 0.013 \\
\hline & Abnormal AC contents & 6 & 30 & 13 & 65 & 0.05 \\
\hline & Posterior synechiae & 0 & 0 & 0 & 0 & 1 \\
\hline & Attached retina & 19 & 95 & 20 & 100 & 0.311 \\
\hline \multirow[t]{8}{*}{ Month 1} & Mean IOP & $14.55 \dagger \dagger$ & - & $14.2+t$ & - & 0.549 \\
\hline & Corneal oedema & 0 & 0 & 2 & 10 & 0.147 \\
\hline & Abnormal AC contents & 3 & 15 & 11 & 55 & 0.019 \\
\hline & Posterior synechiae & 1 & 5 & 0 & 0 & 0.311 \\
\hline & Attached retina & 20 & 100 & 20 & 100 & 1 \\
\hline & Reinjected silicone oil & 1 & 5 & 0 & 0 & 0.311 \\
\hline & Mean LogMAR BCVA & - & - & - & - & 0.263 \\
\hline & Mean postop refraction & - & - & - & - & 0.031 \\
\hline
\end{tabular}

Mean LogMar BCVA: Group A, month $1=0.78$ (3-0.2); Group B, month $1=0.633$ (2.3-0.1).

Mean postop refraction: Group A, month $1=0.75 \mathrm{D}(+1.25$ to $-3.25 \mathrm{D})$; Group B, month $1=-2.5 \mathrm{D}(+1.5$ to $-6.6 \mathrm{D})$.

$B C V A$, best corrected visual acuity; IOP, intraocular pressure; $A C$, anterior chamber.

$\dagger, 10 \mathrm{mmHg}-14 \mathrm{mmHg} ; \uparrow, 3 \mathrm{mmHg}-16 \mathrm{mmHg} ; \S, 12 \mathrm{mmHg}-16 \mathrm{mmHg} ; \uparrow, 10 \mathrm{mmHg}-50 \mathrm{mmHg} ; \dagger, 11 \mathrm{mmHg}-20 \mathrm{mmHg} ; \uparrow+10 \mathrm{mmHg}-20 \mathrm{mmHg}$ 
in the literature. El Baha et al. demonstrated the re-detachment in $6.9 \%(n=3)$ of patients after combined phacoemulsification and SOR, ${ }^{7}$ whilst Scharwey et al. demonstrated re-detachment in $2.7 \%(n=1)$ of patients after silicone removal following a previous combined phacovitrectomy, ${ }^{8}$ and Kaya et al. demonstrated a $2.5 \%(n=3)$ rate of re-detachment after SOR regardless of the timing of phacoemulsification. ${ }^{9}$ The issue with our study that may have influenced a relatively low rate of re-detachment is the short follow-up period after SOR; however, the incidence of re-detachment is known to drop steeply as time progresses after SOR. ${ }^{10}$

The absence of an adequate red reflex due to vitreoretinal pathology is associated with a higher incidence of complications during phacoemulsification..$^{11,12}$ In our study, a direct cause could not be extrapolated to explain complications during phacoemulsification as only one patient who had an extended capsulorhexis had a total RD with a less than adequate red reflex.

One of the issues with a combined phacoemulsification and PPV was intraoperative corneal oedema. In our study, $10 \%$ of patients who had a combined phacoemulsification and PPV developed intraoperative corneal oedema during PPV. Wensheng et al. reported a $3.2 \%$ rate of intraoperative corneal oedema during combined phacoemulsification and PPV for various vitreoretinal pathologies, of which only $17.2 \%$ were RRD. ${ }^{13}$ A main difference there is that all patients had a significant cataract before phacovitrectomy.

One of the advantages of performing a phacovitrectomy over preserving the crystalline lens is the potential to perform a more complete vitrectomy, especially in the region of the vitreous base without risking injury to the crystalline lens. ${ }^{11,14}$ In Group A, one patient had a touch of the posterior capsule of the crystalline lens; however, the capsule was not opened, the lens was preserved and the vitrectomy proceeded. Similarly, in Group B, one patient had a touch to the posterior capsule, which led to an opening in the posterior capsule that was complicated with posterior dislocation of the one-piece IOL. It was retrieved, explanted and a three-piece IOL was implanted in the sulcus. Sood et al. and Scharwey et al. described the implantation of the IOL after fluid-air exchange rather than at the conclusion of phacoemulsification. ${ }^{8,15}$ It is possible that adopting this modification may have prevented unnecessary IOL manipulation, as was experienced in our aforementioned patient. Nonetheless, we preferred implanting the IOL earlier to avoid any difficulty doing so in an air-filled globe. In addition, there is no evidence that it would have reduced the incidence of iatrogenic tears to the posterior capsule during vitrectomy, as IOL implantation in the bag is believed to tighten the posterior capsule and decrease the incidence of iatrogenic posterior capsular tears whilst performing vitrectomy. ${ }^{16}$

In our study, phacovitrectomy was associated with a significantly higher rate of early postoperative AC reaction when compared with vitrectomy alone. Similarly, Yorgun et al. showed a five times increased risk for developing an AC reaction in phacovitrectomy when compared with vitrectomy alone. Their study differed from ours in that they included various vitreoretinal pathologies (half of whom had RRD); all of their patients had a clinically significant cataract; and silicone oil was not the exclusive tamponade. ${ }^{17}$

Postoperative IOP was also an area where the two groups differed. Phacovitrectomy was found to be associated with a significantly higher mean IOP in the early postoperative period when compared with vitrectomy alone. One patient in the phacovitrectomy group developed a pupillary block seven days postoperatively due to posterior synechia. Demetraides et al. and Yorgun et al. also reported one patient each who developed a pupillary block after phacovitrectomy. ${ }^{17,18}$ Non-pupillary block early postoperative elevation of IOP after vitrectomy with silicone oil can be explained by postoperative inflammation, or by the effects of silicone oil that migrates into the anterior chamber and occludes the angle. ${ }^{17,19}$ In phacovitrectomy, retained viscoelastic in the anterior chamber, in addition to the higher rates of inflammation, can explain the higher incidence of early elevation of IOP when compared to vitrectomy alone. ${ }^{17,20}$

Apart from one patient in Group A who had an apparent resolution of postoperative elevated IOP, SOR did not appear to influence IOP elevation. This has been previously reported, such as in the series by Franks et al. They found that SOR was not effective in reversing established glaucoma related to PPV with silicone oil in 120 eyes. ${ }^{21}$ A different finding was reported in an equally large series of patients by Kaya et al., who found that $13.8 \%$ of patients who needed antiglaucoma drugs prior to SOR did not need them afterwards. ${ }^{9}$

In the late postoperative period, a persistent elevation of IOP can be mainly attributed to steroid response, persistent uveitis $^{19}$ or emulsified silicone oil in the anterior chamber. ${ }^{22}$ Accordingly, we could postulate that emulsified silicone oil in the AC was responsible for elevated IOP in one patient in Group A and four patients in Group B. The remaining patient in Group A and three patients in Group B are thought to have steroid-response glaucoma as they did not show any evidence of persistent inflammation.

Postoperative corneal oedema also differed between the two groups. During the whole postoperative period for the first procedure, no patients in Group A developed corneal oedema whilst there was a high rate of corneal oedema in Group B that was statistically significant on day $1(45 \%)$ and day 7 (30\%). The occurrence of postoperative corneal oedema after phacovitrectomy has been reported in non-comparative studies, such as in the work published by Demetriades et al. $(6.7 \%)^{18}$ and retrospective comparative studies reported by Yorgun et al. ${ }^{17}$ The main difference is that all patients in these studies had clinically significant cataracts and different vitreoretinal pathologies - not just RRD. ${ }^{13,18}$

Following SOR, corneal oedema was higher in Group A than in Group B; this remained higher in the first week after SOR. It was expected to be higher in this group because of the effect 
of phacoemulsification, as was seen following combined phacovitrectomy in Group B. The main difference here was the incidence of corneal oedema in Group B despite no phacoemulsification.

It was our postulation that this was related to the presence of emulsified oil in the AC in $50 \%$ of the patients in Group B prior to SOR. Multiple reports of combined phacoemulsification with anterior approach SOR have reported transient postoperative corneal oedema.,23,24 The efflux of silicone oil and its contact with corneal endothelium has been shown to cause endothelial changes, but these changes were not significant when compared to endothelial changes of phacoemulsification alone. ${ }^{25}$ Interestingly, even when silicone oil is removed through the pars plana - as in our patients - corneal oedema has been reported to develop transiently in the postoperative period. ${ }^{26}$

By the end of the 3-month follow-up period, the nine patients who began with clear crystalline lenses had variable degrees of cataracts. This observation in our study differs from most studies in the literature, which reported cataracts forming after PPV with silicone oil tamponade at a mean of six months. ${ }^{1,27,28}$

Functional success, defined by mean BCVA at the final follow-up after SOR, did not appear to be affected by the timing of phacoemulsification. Our rates of $85 \%-90 \%$ improvement of BCVA are consistent with other reports in the literature following SOR, regardless of the timing of phacoemulsification. ${ }^{29,30}$

The refractive outcome one month after SOR was used as an indirect method to demonstrate the accuracy of the preoperative IOL power calculation in both groups. The IOL powers chosen for patients in Group A were selected from biometry performed at the final follow-up before SOR, whilst the retina was attached and the vitreous cavity was full of silicone oil. The IOL powers for patients in Group B were selected from biometry performed before phacovitrectomy, whilst the retina was detached. Biometry was performed using laser interferometry (optical biometry) in all patients. This was based on the theoretical optical principle that the laser beam measures the axial length up to the retinal pigment epithelium and not the internal limiting membrane..$^{31,32}$

The mean spherical equivalent refraction of the patients in Group A was significantly closer to the target of $-0.5 \mathrm{D}$ than in Group B. Based on this, it was concluded that a more accurate IOL power calculation using laser interferometry (optical biometry) could be achieved when biometry was performed with an attached retina, despite the presence of silicone oil. Suzuki et al. and Jeoung et al. have reported a myopic shift in postoperative refraction when phacovitrectomy is compared with cataract surgery alone. ${ }^{33,34}$ Jeoung et al. explored the effect of phacovitrectomy in a wide array of vitreoretinal diseases. A total of $15 \%$ of their patients had RRD and they noticed that the myopic shift was more pronounced with foveal detachment and long axial length. However, they excluded eyes that received silicone oil tamponade. ${ }^{34}$ In our series of patients, only one patient in each group had an attached macula; therefore, the effect of macular attachment could not be assessed as an independent factor influencing the accuracy of the IOL power calculation. An explanation for an artificially shorter axial length and a subsequent myopic shift, as seen in our Group B patients, can be attributed to signals reverberating off the internal limiting membrane in macula-on patients or signals from the detached retina in macula-off patients, resulting in the postoperative refractive surprise. ${ }^{35,36}$

An alternative method for IOL power calculation in the presence of a detached macula is using ultrasound measurements for confirmation and more accuracy, or using the axial length measured in the fellow eye. This method was adopted by Rahman et al. in their series of 95 patients who had phacovitrectomy performed for RRD. Most of the measurements taken from the ultrasound and fellow eye measurements were in patients who had macula-off RRD. They were able to achieve a mean postoperative refractive error of $\pm 1.00 D^{36}$

\section{Conclusion}

This study suggests that the timing of phacoemulsification in patients undergoing PPV for RRD does not affect the structural success or BCVA. More inflammation and elevated IOP, especially in the early postoperative period, were found to be associated with phacovitrectomy. Refraction was more accurate when lens power calculation was performed prior to a combined phaco-silicone removal in silicone oil-filled eyes with an attached retina versus lens power calculation performed prior to combined phacovitrectomy with a detached retina. The main limitations of this study are the relatively short follow-up period, the relatively small number of patients and the fact that biometry was performed exclusively using laser interferometry and was not confirmed with an ultrasound. This study will not alter a surgeon's preference but may help surgeons to make an informed decision based on evidence when faced with this divisive surgical situation.

\section{Acknowledgements}

Prof. Asser Ehsan and Prof. Tamer Macky provided technical surgical support and guidance during the operative procedures performed by the corresponding author. Dr Heba Samir and Dr Mohamed Gaber provided help in the recruitment of patients from the retina clinic.

\section{Competing interests}

The authors have declared that no competing interests exist.

\section{Authors' contributions}

All authors contributed equally to this work. 


\section{Funding information}

This research received no specific grant from any funding agency in the public, commercial or not-for-profit sectors.

\section{Data availability statement}

Data sharing is not applicable to this article.

\section{Disclaimer}

The views and opinions expressed in this article are those of the authors and do not necessarily reflect the official policy or position of any affiliated agency of the authors.

\section{References}

1. Borislav D. Cataract after silicone oil implantation. Doc Ophthalmol 1993;83(1):79-82. https://doi.org/10.1007/BF01203573

2. Hsuan JD, Brown NA, Bron AJ, Patel CK, Rosen PH. Posterior subcapsular and nuclear cataract after vitrectomy. J Cataract Refract Surg. 2001;27(3):437-444. https://doi.org/10.1016/S0886-3350(00)00585-X

3. Riedel KG, Gabel V-P, Neubauer L, Kampik A, Lund O-E. Intravitreal silicone oil injection: Complications and treatment of 415 consecutive patients. Graefes Arch Clin Exp Ophthalmol. 1990;228:19-23. https://doi.org/10.1007/BF02764284

4. Mitry D, Charteris DG, Fleck BW, Campbell H, Singh J. The epidemiology of rhegmatogenous retinal detachment: Geographical variation and clinical associations. Br J Ophthalmol. 2010;94(6):678-684. https://doi.org/10.1136/bjo.2009.157727

5. Suzuki $Y$, Sakuraba T, Mizutani H, Matsuhashi H, Nakazawa M. Postoperative complications after simultaneous vitrectomy and cataract surgery. Ophthalmic Surg Lasers. 2001;32(5):391-396.

6. Suk KK, Murray TM. Combined cataract surgery with pars plana vitrectomy: The vitreoretinal surgeon's perspective. Retin Physician. 2012;9:42-44.

7. El Baha SM, Abouhussein MA, Hemeida TS. Sutureless phacoemulsification with transpupillary removal of silicone oil and intracapsular intraocular lens implantation using illuminated 23-gauge infusion system. Retina. 2011;31(2):408-412. https://doi.org/10.1097//AE.0b013e318200921b

8. Scharwey K, Pavlovic S, Jacobi KW. Combined clear corneal phacoemulsification, vitreoretinal surgery, and intraocular lens implantation. J Cataract Refract Surg. 1999;25(5):693-698. https://doi.org/10.1016/S0886-3350(99)00022-X

9. Kaya M, Özyurt A, Öztürk AT, Er D, Kaynak S, Koçak N. Active silicone oil removal with a transconjunctival sutureless system: Is the 23-gauge system safe and effective? Turkish J Ophthalmol. 2016;46:11-15. https://doi.org/10.4274/tjo.15807

10. Jonas JB, Budde WM, Knorr HLJ. Timing of retinal redetachment after removal of intraocular silicone oil tamponade. Am J Ophthalmol. 1999;128(5):628-631. https://doi.org/10.1016/S0002-9394(99)00201-9

11. Steel DHW. Phacovitrectomy: Expanding indications. J Cataract Refract Surg. 2007;33(6):933-936. https://doi.org/10.1016/j.jcrs.2007.01.047

12. Nagpal MP, Mahuvakar SA, Chaudhary PP, Mehrotra NS, Jain AK. Chandelier assisted retroillumination for phacoemulsification in phacovitrectomy. Indian Ophthalmol. 2018;66(8):1094-1097. https://doi.org/10.4103/ijo.IJO_85_18

13. Wensheng $L$, Wu R, Wang $X, X u M$, Sun $G$, Sun C. Clinical complications of combined phacoemulsification and vitrectomy for eyes with coexisting cataract and vitreoretinal diseases. Eur J Ophthalmol. 2009;19(1):37-45. https://doi. org/10.1177/112067210901900106

14. Caiado RR, Magalhães Jr O, Badaró E, et al. Effect of lens status in the surgical success of 23-gauge primary vitrectomy for the management of rhegmatogenous retinal detachment: The Pan American Collaborative Retina Study (PACORES) group results. Retina. 2015;35(2):326-333. https://doi.org/10.1097/IAE.0000000000000307

15. Sood V, Rahman R, Denniston AK. Phacoemulsification and foldable intraocular lens implantation combined with 23-gauge transconjunctival sutureless vitrectomy. Cataract Refract Surg. 2009;35(8):1380-1384. https://doi.org/10.1016/j.jcrs.2009. 02.047
16. Kim SH, Chung JW, Chung H, Yu HG. Phacoemulsification and foldable intraocular lens implantation combined with vitrectomy and silicone oil tamponade for severe proliferative diabetic retinopathy. J Cataract Refract Surg. 2004;30(8): 1721-1726. https://doi.org/10.1016/j.jcrs.2003.12.042

17. Yorgun MA, Toklu Y, Mutlu M, Ozen U. Clinical outcomes of 25-gauge vitrectomy surgery for vitreoretinal diseases: Comparison of vitrectomy alone and phacovitrectomy. Int J Ophthalmol. 2016;9(8):1163-1169.

18. Demetriades AM, Gottsch JD, Thomsen R, et al. Combined phacoemulsification, intraocular lens implantation, and vitrectomy for eyes with coexisting cataract and vitreoretinal pathology. Am J Ophthalmol. 2003;135(3):291-296. https://doi. org/10.1016/S0002-9394(02)01972-4

19. Honavar SG, Goyal M, Majji AB, Sen PK, Naduvilath T, Dandona L. Glaucoma after pars plana vitrectomy and silicone oil injection for complicated retinal detachments. Ophthalmology. 1999;106(1):169-177. https://doi.org/10.1016/ S0161-6420(99)90017-9

20. Laurell C-G, Zetterström C. Inflammation and blood-aqueous barrier disruption. Cataract Refract Surg. 2000;26(3):306-307. https://doi.org/10.1016/S0886-3350 (00)00347-3

21. Franks WA, Leaver PK. Removal of silicone oil-Rewards and penalties. Eye. 1991;5(3):333-337. https://doi.org/10.1038/eye.1991.53

22. Al-Jazzaf AM, Netland PA, Charles S. Incidence and management of elevated intraocular pressure after silicone oil injection. J Glaucoma. 2005;14(1):40-46. https://doi.org/10.1097/01.ijg.0000145811.62095.fa

23. Frau $E$, Lautier-Frau $M$, Labetoulle $M$, Hutchinson $S$, Offret $H$. Phacoemulsification combined with silicone oil removal through the posterior capsulorhexis tear. Retina. 2002;22(2):158-162. https://doi.org/10.1097/00006982-2002040 tear. Retina. 000004

24. Zhu Y-C, Yuan D-Q, Xie P, Liu X-Y, Yuan S-T, Liu Q-H. Phacoemulsification combined with transpupillary removal of silicone oil and intracapsular intraocular lens implantation. Int J Ophthalmol. 2017;10(11):1693-1697.

25. Boscia F, Recchimurzo N, Cardascia N, Sborgia L, Ferrari TM, Sborgia C. Phacoemulsification with transpupillary silicone oil removal and lens implantation through a corneal incision using topical anesthesia. J Cataract Refract Surg. 2003;29(6):1113-1119. https://doi.org/10.1016/S0886-3350(03) 00067-1

26. Suarez-Tata M, Villaseñor-Díez J, Suárez-Tatá LM, et al. Phacoemulsification cataract surgery in vitrectomized eyes. Arch Soc Esp Oftalmol. 2004;79(11):531-536. https://doi.org/10.4321/S0365-66912004001100004

27. Shah MA, Khan B, Nawaz F, Rahman M. Frequency of complications of silicone oil in the surgical treatment of rhegmatogenous retinal detachment. Pakistan Ophthalmol. 2017;33(2):74-78.

28. Federman JL, Schubert HD. Complications associated with the use of silicone oil in 150 eyes after retina-vitreous surgery. Ophthalmology. 1988;95(7):870-876. https://doi.org/10.1016/S0161-6420(88)33080-0

29. Tavares RLDP, Nóbrega MJ, Nóbrega FAJ, De Novelli FJ, De Oliveira CAC. Timing and outcomes after silicone oil removal in proliferative vitreoretinopathy: A retrospective clinical series. Int J Retin Vitr. 2015;1:2. https://doi.org/10.1186/ s40942-015-0002-y

30. Rhatigan $M$, McElnea $E$, Murtagh $P$, et al. Final anatomic and visual outcomes appear independent of duration of silicone oil intraocular tamponade in complex retinal detachment surgery. Int J Ophthalmol. 2018;11(1):83-88.

31. Lee AC, Qazi MA, Pepose JS. Biometry and intraocular lens power calculation. Curr Opin Ophthalmol. 2008;19(1):13-17. https://doi.org/10.1097/ICU.0b013e 3282f1c5ad

32. Shiraki N, Wakabayashi T, Sakaguchi H, Nishida K. Optical biometry-based intraocular lens calculation and refractive outcomes after phacovitrectomy for rhegmatogenous retinal detachment and epiretinal membrane. Sci Rep. 2018;8:11319. https://doi.org/10.1038/s41598-018-29553-w

33. Suzuki $Y$, Sakuraba T, Mizutani $H$, Matsuhashi $H$, Nakazawa M. Postoperative refractive error after simultaneous vitrectomy and cataract surgery. Ophthalmic Sur. Lasers Imaging Retin. 2000;31(4):271-275.

34. Jeoung JW, Chung H, Yu HG. Factors influencing refractive outcomes after combined phacoemulsification and pars plana vitrectomy: Results of a prospective study. J Cataract Refract Surg. 2007;33(1):108-114.

35. Lege BAM, Haigis W. Laser interference biometry versus ultrasound biometry in certain clinical conditions. Graefe's Arch Clin Exp Ophthalmol. 2004;242:8-12. https://doi.org/10.1007/s00417-003-0672-2

36. Rahman R, Bong CX, Stephenson J. Accuracy of intraocular lens power estimation in eyes having phacovitrectomy for rhegmatogenous retinal detachment. Retina. 2014;34(7):1415-1420. https://doi.org/10.1097/IAE.0000000000000072 